Tersedia online di: http://ejournal-balitbang.kkp.go.id/index.php/JP
e-mail:jurnalpari@gmail.com
JURNAL PARI
volume 5 Nomor 1 Juli 2019
p-ISSN: 2502-0730
e-ISSN : 2549-0133

\title{
KEBUTUHAN INFORMASI PEMUSTAKA DI BALAI BESAR RISET BUDIDAYA LAUT DAN PENYULUHAN PERIKANAN (BBRBLPP)
}

\author{
Ketut Masiani \\ Balai Besar Riset Budidaya Laut dan Penyuluhan Perikanan \\ Diterima tanggal : 10 Juni 2019 Diterima setelah perbaikan : 20 Juni 2019 \\ disetujui terbit : 12 Juli 2019
}

\begin{abstract}
ABSTRAK
Perpustakaan memiliki tugas dan kewajiban menyedikan koleksi dan informasi yang dibutuhkan oleh pemustaka. Permasalahan yang sering dihadapi oleh pengelola perpustakaan BBRBLPP yaitu tidak terpenuhi kebutuhan pemustaka karena koleksi yang dibutuhhkan tidak tersedia, koleksi di perpustakaan tidak sesuai dengan kebutuhan pemustaka. Untuk mengetahui kebutuhan pemustaka ini dilakukan pengkajian kebutuhan pemustaka dengan mengkaji peminjaman koleksi oleh pemustaka dari tahun 2015-2018 dan kemudian membandingkan dengan rencana strategis (renstra) BBRBLPP 2015-2018. Tujuan analisis kebutuhan pemustaka ini adalah untuk mengetahui keterkaitan kegiatan riset di BBRBLPP dengan topik koleksi yang dipinjam pemustaka. Hasil menunjukkan bahwa koleksi yang banyak diminati/banyak dipinjam oleh pemustaka merupakan komoditas/topik yang tercantum dalam rencana strategis BBRBLPP yaitu sebesar $78 \%$ dibandingkan dengan topik yang di luar renstra yaitu sebesar $22 \%$ dari total jumlah pemimjaman tahun 2015-2018. Renstra BBRBLPP dapat digunakan sebagai salah satu acuan untuk pengembangan bahan koleksi di perpustakaan BBRBLPP
\end{abstract}

Kata kunci: kebutuhan; koleksi; peminjaman; pemustaka.

\section{ABSTRACT}

The library has duty and obligation to provide collections and information needed by the user. The problem that is often faced by the IMRAFE library is that the needs of the user are not met because the collections are not available nor the collections in the library are not in accordance with the needs of the users. To find out the user's needs, a study of the needs of users is carried out by examining the borrowing collections by the users in the periode of the year 2015-2018 and then comparing them with the 2015-2018 IMRAFE strategic plans. The purpose of this analysis is to find out the relevance of research activities at the IMRAFE with the topic of collections borrowed by users. The results show that the collections that are in great demand / borrowed by the users are the commodities / topics listed in the IMRAFE strategic plan, which is $78 \%$ compared to topics outside the strategic plan of 22\% of the total year 2015-2018. IMRAFE strategic plans can be used as one of the references for the development of collection in the IMRAFE library.

Keywords: need assessment; library user; information resources; collections development. 


\section{PENDAHULUAN}

Pemustaka merupakan salah satu bagian dari sistem perpustakaan. Secara umum perpustakaan terdiri dari gedung, koleksi, pemustaka dan pengelola perpustakaan/pustakawan. Komponen ini akan saling mempengaruhi dalam kegiatannya. Sebuah perpustakaan akan berfungsi apabila dalam perpustakaan ada koleksi dan ada pemustakanya serta ada pustakawanya atau pengelolanya. Salah satu hal penting yang perlu dipahami oleh pengelola perpustakaan adalah mengenai perilaku pemustakanya. Hal ini akan sangat menunjang keberhasilan dalam pelayanan perpustakaan. Memahami perilaku pemustaka juga akan dapat memberikan arah kepada pengelola mengenai kebutuhan dari pemustakanya sehingga pengelola mampu menelusuri/mencari, memberikan atau menyebarkan infromasi yang tepat sesuai dengan kebutuhan pemustaka. Kebutuhan pemustaka terhadap suatu informasi dipengaruhi oleh beberapa faktor diantaranya pekerjaan, organisasi, kualifikasi pribadi, dan pendidikan. Perpustakaan BBRBLPP yang berada pada lembaga riset, pemustakanya terdiri dari peneliti, teknisi litkayasa, mahasiswa magang/ penelitian serta masyarakat umum. Secara umum koleksi yang dibutuhkan oleh pemustaka merupakan koleksi yang mendukung kegiatan riset peneliti.

Untuk mengoptimalkan pelayanan dalam penyediaan informasi yang dibutuhkan pemustaka pengelola perpustakaan harus responsive terhadap kebutuhan pemustaka sehingga mampu menyediakan kebutuhan peustaka baik untuk saat ini maupun yang akan datang. Berkaitan dengan pemanfaatan koleksi ini, Lancaster dalam Maraharja (2013) berpendapat bahwa terdapat empat faktor yang mempengaruhi pemanfaatan perpustakaan, yaitu

(1) koleksi yang berkaitan dengan ketersediaan subjek tertentu, jumlah, kelengkapan, edisi dan bahasa,

(2) faktor aksesibilitas terhadap alat bantu temu kembali maupun terhadap penempatan buku di rak, aturan peminjaman serta waktu layan perpustakaan,

(3) faktor sumber daya manusia perpustakaan khususnya jumlah, pengetahuan terhadap substansi koleksi, bersifat membantu dan ramah,

(4) faktor pemustaka terutama karakteristik pemustaka, meliputi pendidikan, pekerjaan, sosial ekonomi dan kebutuhan informasinya

\section{Deskripsi Permasalahan}

Mengetahui kebutuhan pemustaka merupakan salah satu tahap awal yang perlu dipahami pengelola perpustakaan dalam menyediakan bahan koleksi di perpustakaannya. Salah satu metode untuk mengetahui kebutuhan pemustaka yaitu melakukan analisis kebutuhan koleksi yang dapat dilakukan melalui analisis koleksi yang dipinjam pemustaka.

Beberapa permasalahan yang sering terjadi dalam layanan perpustakaan BBRBLPP adalah tidak terpenuhinya kebutuhan pemustaka yang diakibatkan tidak adanya ketersedian koleksi yang dibutuhkan pemustaka. Salah satu upaya untuk mengetahui kebutuhan pemustaka ini dilakukan dengan menganalisis kebutuhan pemustaka melalui analisis peminjaman koleksi. Tujuan analisis ini adalah untuk mengetahui keterkaitan kegiatan riset pada tahun tertentu dengan koleksi yang dibutuhkan pemustaka sehingga perpustakaan kedepannya dapat menyediakan koleksi yang dibutuhkan pemustaka sesuai dengan kegiatan riset yang akan dilakukan.

\section{TINJAUAN PUSTAKA}

Koleksi perpustakaan memegang peranan penting dalam optimalitas pelayanan perpustakaan. Informasi merupakan alasan dan kebutuhan pemustaka untuk datang ke perpustakaan. Untuk itu perpustakaan perlu menyediakan berbagai koleksi informasi yang dibutuhkan pemustaka sehingga mampu memenuhi kebutuhan pemustaka serta mampu meningkatkan pelayanan kepada pemustaka. Perpustakaan juga perlu menyediakan informasi yang berkualitas yang mampu mendukung kegiatan riset yang dilakukan oleh peneliti. Sutarno (2005) menyebutkan bahwa koleksi perpustakaan harus kuat, dalam pengertian hal, jumlah, jenis, ragam, dan mutu. Menilik pendapat ini perpustakaan wajib menyediakan beragam informasi dan koleksi baik dari segi jumlah, kualitas, bentuk dan sumber sesuai dengan kebutuhan pemustaka.

Salah satu cara untuk menyediakan koleksi adalah melalui pengembangan koleksi bahan pustaka. Salah satu tahap penting dalam pengembangan koleksi adalah kegiatan seleksi bahan pustaka yang akan disediakan perpustakaan kepada pemustaka. Pengelola perpustakaan dalam pengembangan koleksi wajib memiliki pengetahuan tentang kebutuhan pemustaka, kemuktahiran informasi yang berkembang, jenis dan bentuk informasi yang tersedia serta sumber informasi yang ada. Seperti yang diungkapkan Siregar (1998) dalam melaksanakan seleksi bahan pustaka hendaknya memperhatikan pedoman dalam penentuan kebijakan pengembangan koleksi, antara lain:

Relevansi (kesesuaian) yaitu penyediaan koleksi perpustakaan yang sesuai dengan kebutuhan pemustaka. Relevansi dalam penyediaan bahan 
pustaka mutlak dibutuhkan mengingat tujuan utama penyediaan koleksi perpustakaan adalah dapat dimanfaatkannya koleksi yang ada oleh pemustaka dan terpenuhinya kebutuhan pemustaka.

Kelengkapan yaitu koleksi perpustakaan harus beragam baik dari segi isi, bentuk dalam artian bahwa koleski yang ada diperpustakaan tidak hanya terdiri dari buku-buku teks tetapi juga berbentuk digital dan lain-lain serta koleksi yang tersedia memuat informasi beragam yaitu menyangkut bidang ilmu lain namun berkaitan dengan tupoksi lembaga.

Kemutahiran yaitu perpustakaan harus selalu menyediakan koleksi yang memuat informasi terbarukan seiring dengan ilmu pengetahun dan teknologi yang sedang berkembang

Kerjasama dalam artian kerjasama antara pihakpihak yang terlibat yaitu pustakawan, pemustaka, serta beberapa pihak yang berkompeten agar koleksi yang disajikan dapat memenuhi kebutuhan pengguna.

Alat bantu seleksi. Alat bantu seleksi merupakan sarana yang dapat memudahkan mengetahui informasi koleksi secara lengkap, sehingga akan mempermudah kegiatan pengembangan koleksi.

\section{Kebutuhan}

Kebutuhan merupakan sesuatu hal yang diperlukan oleh seseorang dalam kegiatan tertentu untuk mencapai tujuan kegiatan yang dilakukannya. Kebutuhan dari konteks perpustakaan merupakan kebutuhan informasi yang diartikan sebagai kondisi ketertarikan atau keinginan terhadap informasi tertentu yang termuat dalam suatu pustaka/sumber informasi yang dapat memberikan jawaban dan kepuasan terhadap keingintahuan tentang sesuatu hal. Kebutuhan informasi ini dapat mendorong seseorang untuk berusaha memenemukan informasi yang dibutuhkan sehingga tujuan yang diinginkan dapat terwujud. Qalyubi (2007) menyebutkan kebutuhan informasi didorong oleh apa yang dinamakan sebagai, "a problematic" yaitu situasi yang terjadi dalam diri manusia (pada lingkungan internalnya) yang dirasakan tidak memadai oleh manusia yang bersangkutan untuk mencapai tujuan tertentu dalam hidupnya.

\section{Informasi}

Secara umum informasi merupakan suatu data, fakta yang memiliki makna bagi penggunanya. Kadir (2002), mendefinisikan informasi adalah data yang telah diproses sedemikian rupa sehingga meningkatkan pengetahuan seseorang yang menggunakan data tersebut. Berbagai hal dalam kehidupan ini bisa menjadi informasi ketika seseorang mengolah data/fakta yang ada menjadi hal yang berguna bagi penerimanya dan bermanfaat dalam pengambilan keputusan serta mampu memberikan kepuasan kepada seseorang yang membutuhkan informasi tersebut.

Dari sudut pandang dunia kepustakawan dan perpustakaan, informasi adalah suatu rekaman fenomena yang diamati, atau bisa juga berupa putusan-putusan yang dibuat seseorang (Yusup, 2009). Pada perpustakaan rekaman fenomena yang diamati/informasi merupakan salah satu komponen perpustakaan yang memiliki peran utama dalam keberadaan perpustakaan. Hal ini terkait dengan peran, tugas dan fungsi dari perpustakaan yaitu sebagai tempat pemenuhan kebutuhan informasi bagi pemustakanya

\section{Kebutuhan informasi}

Salah satu tindakan yang bisa dilakukan untuk mengoptimalkan perpustakaan dalam memenuhi kebutuhan pemustaka adalah identintifikasi kebutuhan informasi oleh pemustaka. Grover dalam Deanawa (2017), menyatakan bahwa proses identifikasi kebutuhan informasi merupakan proses manajemen yang bertujuan agar lembaga informasi terkait dapat menjalankan perannya dalam melayani segala lapisan masyarakat tanpa terkecuali, serta dapat memenuhi konsep fundamental dalam hal pemasaran, yakni berfokus pada pelanggan. Senada dengan itu Qalyubi (2007), menyebutkan bahwa untuk memenuhi kebutuhan informasi bagi pemustaka, perpustakaan harus mampu mengkaji, menganalisis siapa pemustaka dan informasi apa yang di perlukan, mengusahakan tersedianya jasa pada saat yang diperlukan, dan mendorong pemustaka untuk menggunakan fasilitas yang disediakan perpustakaan.

Seperti yang telah diungkapkan bahwa salah satu komponen utama yang di perpustakaan adalah informasi serta pemustaka. Komponen ini memiliki kaitan yang sangat erat mengingat setiap pemustaka memiliki kebutuhan terhadap informasi. Secara umum kebutuhan informasi setiap orang berbeda-beda. Secara detail disampaikan oleh Basuki (1991), bahwa kebutuhan informasi adalah informasi yang diinginkan seseorang untuk pekerjaan, penelitian, kepuasan rohani, pendidikan dan lain-lain. Kebutuhan informasi ini akan muncul seiring dengan kegiatan yang dilakukan oleh seseorang sehingga memunculkan keinginan/ketertarikan terhadap suatu informasi dalam upaya untuk mencapai tujuannya/mencapai 
kepuasan. Fatmawati (2015) juga mengungkapkan bahwa kebutuhan informasi seseorang akan muncul manakala ada kesenjangan antara pengetahuan yang dimiliki dengan pengetahuan yang diinginkan sehingga seiring dengan keinginan seseorang untuk mencari jawaban atas pertanyaannya, dia akan terus menggali informasi yang diinginkan untuk menjawab semua ketidaktahuannya. Sementara Wilson dalam Ishak (2006) menyebutkan beberapa faktor yang mempengaruhi kebutuhan informasi antara lain:

a. Kebutuhan individu (person).

Kebutuhan yang ada dalam diri individu meliputi:

a.1. kebutuhan psikologis (psychological needs), merupakan kebutuhan yang ditimbulkan terkait dengan kebiasaan seseorang atau kebutuhan dasar

a.2. kebutuhan afektif (affectif needs) yaitu kebutuhan yang dikaitkan dengan kepercayaan, kreditbilitas dan status individu (hasrat untuk harga diri),

a.3. kebutuhan kognitif (cognitive needs) yaiu kebutuhan dasar untuk ingin tahu dan mengerti pada hal tertentu dengan melakukan usaha-usaha tertentu salah satunya proses pembelajaran

b. Peran sosial (social role).

Peran sosial (social role) ini terkait dengan peran kerja (work role) dan tingkat kinerja (performance level), yang disandang/dimiliki oleh seseorang misalnya peneliti, mahasiswa, teknisi dan lain-lain

c. Lingkungan (environment).

Faktor lingkungan yang meliputi

c.1. lingkungan kerja (work environment),

c.2. lingkungan sosial-budaya (social-cultural environment),

c.3. lingkungan politik-ekonomi (politic-economic environment)

Di sisi lain, Crowford dalam Devadason (1996) menyebutkan bahwa kebutuhan informasi seseorang bergantung kepada 10 (sepuluh) hal yang berkenaan dengan individu sebagai berikut:

1. Work activity (aktivitas pekerja)

2. Discipline/ Field / Area of interest (Disiplin/ lapangan/area ketertarikan)

3. Availability of facilities (Ketersediaan fasilitas)

4. Hierarchical position of individuals (Posisi hirarki seorang individu)

5. Motivation factors for information needs (faktor motivasi terhadap kebutuhan informasi)

6. Need to take a decision (kebutuhan untuk membuat keputusan)

7. Need to seek new ideas (kebutuhan dalam mencari ide baru)

8. Need to validate the correct ones (kebutuhan untuk mempalidasikan agar sesuatu menjadi benar)
9. Need to make professional contributions (kebutuhan untuk membuat kontribusi yang professional)

10. Need to establish priority for discovery etc (kebutuhan untuk membangun prioritas dalam penemuan, dan sebagainya).

Sedangkan menurut Voight dalam Krikelas (1983) seseorang (individu) membutuhkan informasi karena tiga macam kebutuhan, yaitu:

1. Kebutuhan untuk menyelesaikan suatu penelitian ilmiah yang sedang dilakukan.

2. Kebutuhan informasi yang ditimbulkan dari pekerjaannya maupun profesi.

3. Kebutuhan informasi yang relevan dengan suatu subyek tertentu yang menjadi perhatian seseorang.

Dari beberapa pendapat para ahli diatas secara umum kebutuhan informasi seseorang dapat di pengaruhi oleh pekerjaan/peran, lingkungan sosial, dan perkembangan ilmu pengetahuan.

\section{METODE}

\section{Sumber Data}

Data yang digunakan dalam analisis ini berasal dari data primer dan sekunder. Data primer yang digunakan diantaranya data kegiatan riset yang tercantum dalam RENSTRA BBRBLPP tahun 20152019 serta data pelayanan sirkulasi di perpustakaan BBRBLPP. Sedangkan data sekunder diperoleh melalui studi pustaka/studi literature yang terkait dengan pengkajian ini baik dalam bentuk tercetak maupun online.

\section{Teknik Pengumpulan Data}

Teknik pengumpulan data merupakan kegiatan dalam rangka memperoleh data atau informasi yang lengkap dan akurat yang mampu memberikan informasi yang terkait dengan kegiatan anallisis ini. Pengumpulan data yang digunakan dalam anaisis ini dilakukan dengan mengumpulkan data-data dari kegiatan layanan sirkulasi dari tahun 2015 sampai dengan tahun 2018 dengan memuat informasi antara lain pemustaka yang melakukan peminjaman, jenis koleksi yang dipinjam, judul/topik koleksi yang dipinjam pemustaka.

\section{Teknik Analisis Data}

Analisis data merupakan tahap proses pengolahan dan proses analisis terhadap data yang telah dikumpulkan sesuai dengan data yang dibutuhkan. Dalam analisis ini data yang telah terkumpulkan 
dianalisis sesuai topik dari koleksi yang terbanyak dipinjam kemudian membandingkan topik pinjaman yang terjadi setiap tahun dan mengaitkan dengan renstra 2015-2019.

\section{Penyajian Data}

Data dalam pengkajian ini dibuat dalam bentuk tabel yang memuat informasi pemustaka, judul koleksi serta topik koleksi yang dipinjam dan hasil analisa kemudian disajikan kedalam bentuk grafik.

\section{HASIL DAN PEMBAHASAN}

Perpustakaan BBRBLPP merupakan perpustakaan khsusus pada Balai Besar Riset Budidaya Laut dan Penyuluhan Perikanan yang memiliki tupoksi dalam mendukung kegiatan penelitian dan pengembangan dalam bidang budidaya laut. Dalam melaksanakaan kegiatannya perpustakaan BBRBLPP melayani pemustaka yang terdiri dari peneliti, teknisi litkayasa dan mahasiswa yang sedang melakukan kegiatan magang/PKL/ Penelitian di BBRBLPP serta masyarakat umum seperti petani, mahasiswa dan lain-lain. Sebagaiman tercantum dalam peraturan Kepala perpustakaan Nasional Republik Indonesia Nomor 14 Tahun 2017 tentang standar nasional perpustakaan khusus bahwa tugas perpustakaan khusus adalah melayani pemustaka dengan menyedikan bahan perpustakaan/ bacaan yang sesuai dengan kebutuhan lembaga induk dan masyarakat di sekitarnya. Dengan demikian perpustakaan BBRBLPP wajib menyediakan koleksi yang mendukung kegiatan penelitian yang dilakukan di BBRBLPP mengingat koleksi yang ada diperpustakaan merupakan bahan acuan dalam kegiatan penelitian serta sumber inspirasi bagi pemustaka/peneliti sehingga peneliti mampu terus berinovasi dan menghasilkan hasil penelitian yang terbarukan dan bernilai tinggi. Pengelola perpustakaan harus memiliki jiwa "Be Proactive" yaitu mampu menangkap fenomena yang terjadi di sekitar pemustaka dan mampu menangkap trending topik yang ada (Glossop dalam Puspitasari, 2015). Trending topik dalam hal ini dapat dilihat dari topik-topik yang banyak diminati oleh pemustaka dari layanan sirkulasi.

Berdasarkan data yang dikumpulkan dari catatan peminjaman koleksi perpustakaan BBRBLPP diperoleh data jumlah topik yang paling sering dipinjam oleh pemustaka pada tahun 2015-2018 sebagaimana tercantum pada gambar 1 .

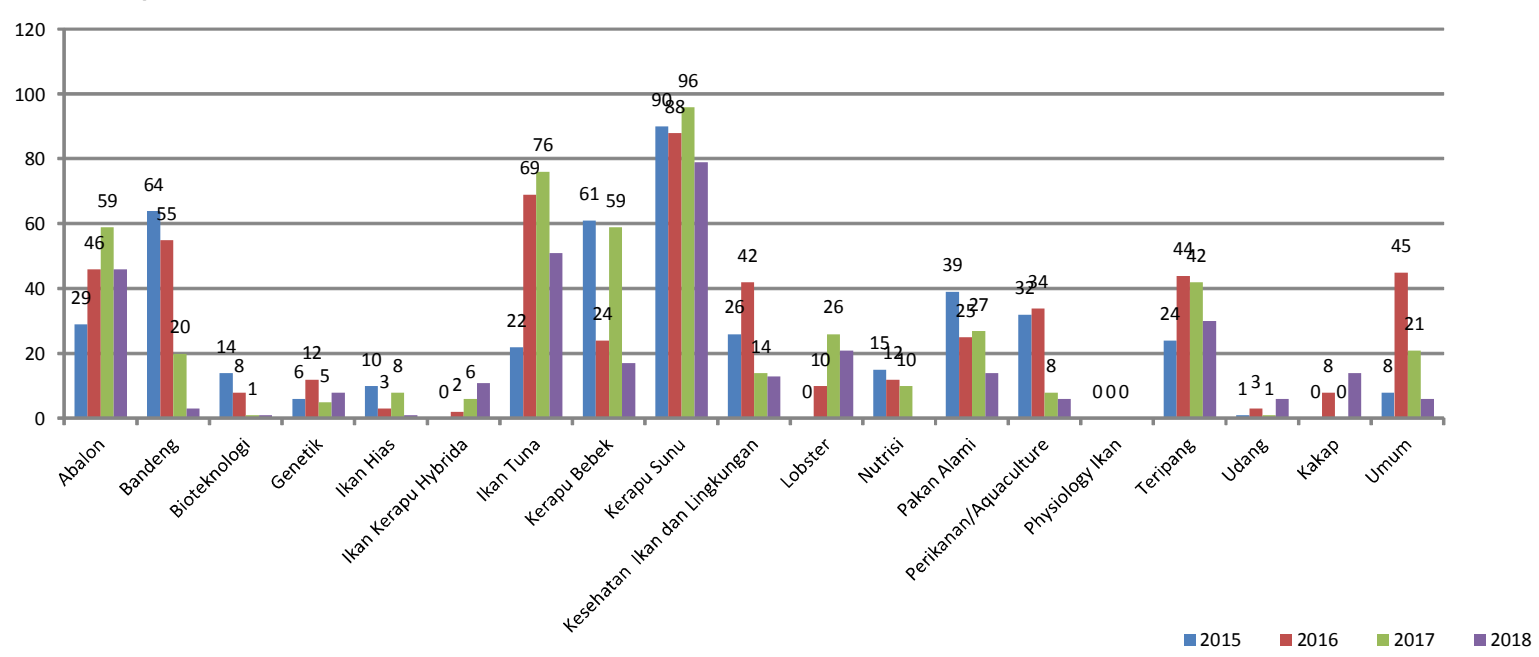

Gambar 1. Jumlah topik koleksi yang dipinjam tahun 2015-2018

Dari grafik diatas dapat terlihat bahwa pada tahun 2015 topik koleksi yang paling sering dipinjam yaitu kerapu sunu (90 kali), bandeng ( 64 kali), kerapu bebek (61 kali), pakan alami (39 kali), aquaculture (koleksi yang terkait dengan perikanan dan kelautan secara umum) (32 kali), abalone (29 kali), kesehatan lingkungan (26 kali), teripang (24 kali) dan ikan tuna (22 kali). Pada tahun 2016 topik yang paling sering dipinjam yaitu kerapu sunu (88 kali), ikan tuna (69 kali), bandeng ( 55 kali), abalone (46 kali), buku umum (buku lain yang tidak terkait tentang perikanan kelautan) (45 kali), teripang (44 kali), penyakit dan kesehatan ikan (42 kali), aquaculture (koleksi yang terkait dengan perikanan dan kelautan secara umum) (34 kali). Tahun 2017 topik yang paling banyak dipinjam adalah kerapu sunu (90 kali), ikan tuna (76 kali), abalon (59 kali), kerapu bebek (59 kali), teripang (42 kali), pakan alami (27 kali), lobster (26 kali) dan buku umum (21 kali). Sedangkan pada tahun 2018 topik koleksi yang paling sering terpinjam yaitu: kerapu sunu (79 kali), Tuna (51 kali), Abalon (46 kali), Teripang (30 kali) dan Lobster (21 kali). 


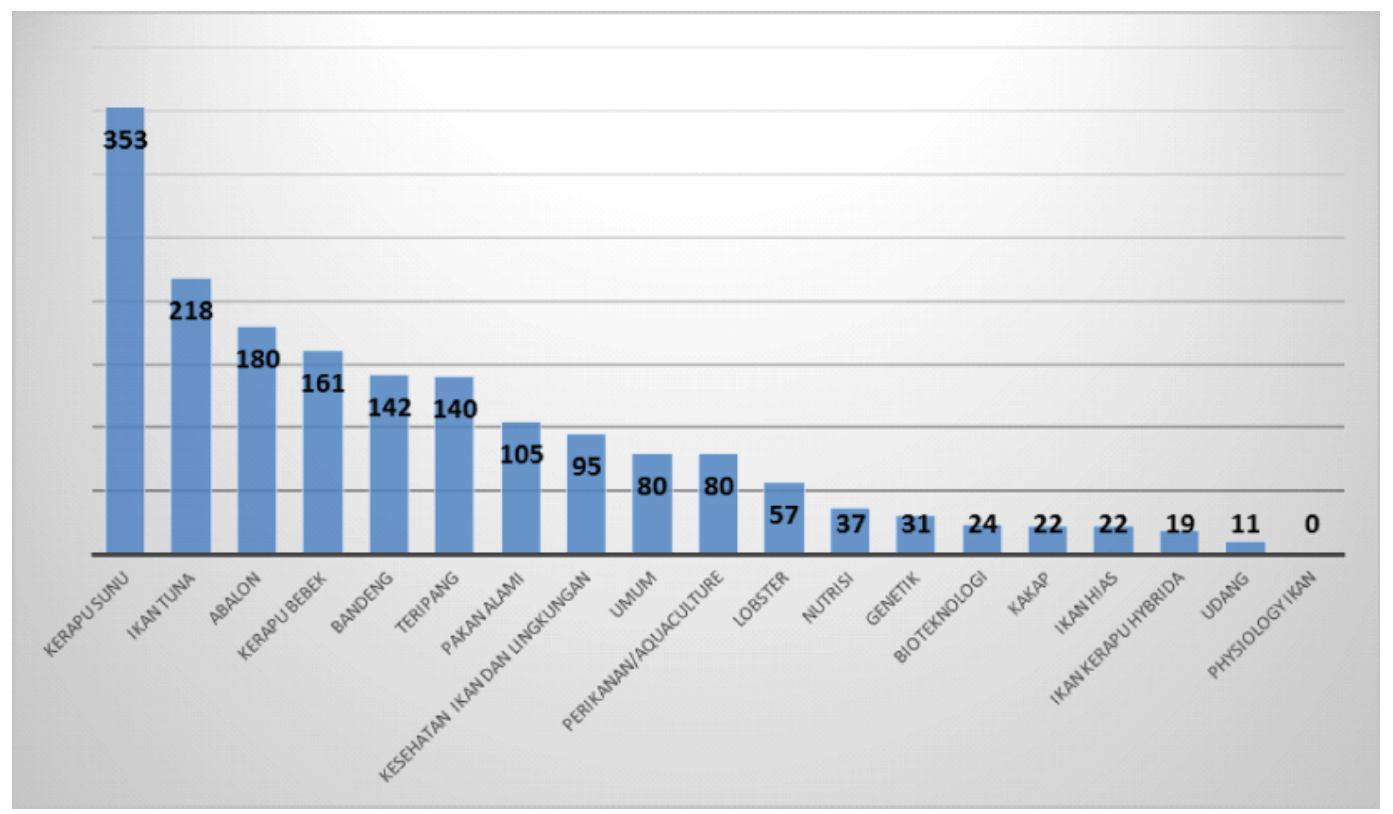

Gambar 2. Jumlah topik koleksi yang dipinjam tahun 2015-2018 secara keseluruhan

Gambar 2. menunjukkan bahwa dalam kurum waktu dari tahun 2015-2018 topik yang paling banyak dipinjam oleh pemustaka adalah koleksi yang membahas tentang Kerapu Sunu (353 kali), Ikan Tuna Sirip Kuning (218 kali), Abalon (180 kali), Kerapu Bebek (161 kali), Bandeng (142 kali), Teripang (140 kali), pakan alami (105 kali) serta penyakit dan kesehatan lingkungan (95 kali).

Berdasarkan Renstra BBRBLPP tahun 2015-2019, kegiatan penelitian yang dilakukan BBRBLPP adalah penelitian komoditas bandeng, tuna sirip kuning, abalon, kerapu sunu, teripang, lobster, dan scalopps dengan 4 kelompok kegiatan strategis penelitian yaitu genetik, breeding dan bioteknologi, penelitian nutrisi dan teknologi pakan, penelitian dan pengembangan teknologi budidaya, serta penelitian kesehatan ikan dan lingkungan budidaya.

Berdasarkan renstra tersebut topik-topik koleksi yang dipinjam dalam kurun waktu 2015-2018 dapat dilihat dalam tabel 1.

Tabel 1. Jumlah peminjaman koleksi tahun 2015-2018 berdasarkan keberadaan topik dalam renstra BBRBLPP 2015-2018

\begin{tabular}{|l|r|l|}
\hline Topik & Jumlah & Topik Dalam Renstra BBRBLPP \\
\hline Kerapu Sunu & 353 & Penelitian komoditas Kerapu Sunu \\
\hline Ikan Tuna & 218 & Penelitian komoditas Ikan Tuna \\
\hline Abalon & 180 & Penelitian komoditas Abalon \\
\hline Bandeng & 142 & Penelitian komoditas Bandeng \\
\hline Teripang & 140 & Penelitian komoditas Teripang \\
\hline Pakan Alami & 105 & Penelitian Nutrisi dan teknologi pakan \\
\hline Kesehatan Ikan dan Lingkungan & 95 & Penelitian Kesehatan Ikan dan Lingkungan \\
\hline Lobster & 57 & Penelitian genetik, breeding dan bioteknologi \\
\hline Nutrisi & 37 & Penelitian Nutrisi dan teknologi pakan \\
\hline Genetik & 31 & Penelitian genetik, breeding dan bioteknologi \\
\hline Bioteknologi & 24 & Penelitian genetik, breeding dan bioteknologi \\
\hline Kerapu Bebek & 161 & - \\
\hline Perikanan/Aquaculture & 80 & Penelitian genetik, breeding dan bioteknologi \\
\hline Umum & 80 & - \\
\hline Ikan Hias & 22 & - \\
\hline Kakap & 22 & - \\
\hline Ikan Kerapu Hybrida & 19 & - \\
\hline Udang & 11 & - \\
\hline
\end{tabular}


Tabel 1. memperlihatkan bahwa topik-topik sering dipinjam adalah topik yang tercantum dalam renstra (merupakan fokus komoditas) kegiatan penelitian BBRBLPP. Topik koleksi yang terdapat dalam renstra yang paling banyak dipinjam adalah kerapu sunu sebanyak 353 kali sedangkan topik koleksi yang tidak terdapat dalam renstra yang banyak dipinjam adalah kerapu bebek sebanyak 161 kali. Topik yang banyak peminat namun tidak terdapat dalam renstra 20152019 adalah topik yang kegiatan penelitiannya dilaksanakan pada tahun-tahun sebelumnya.

Secara keseluruhan jumlah minat pada pada koleksi yang tercantum dalam renstra dan diluar renstra dapat digambarkan dalam grafik dibawah ini.

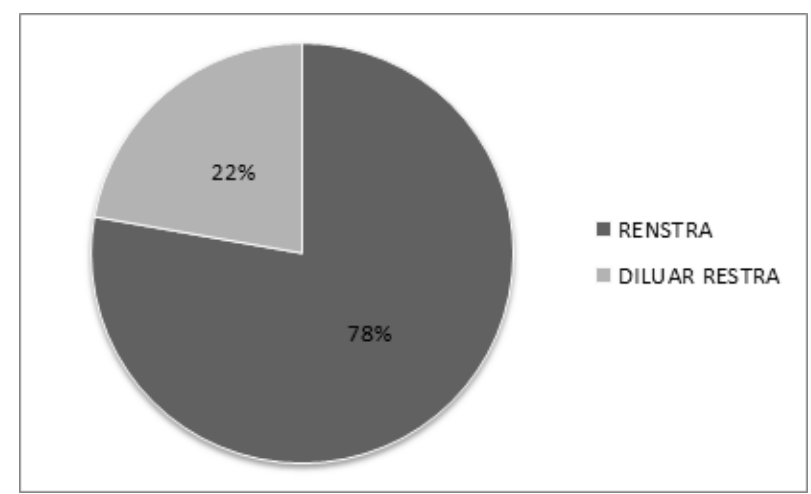

Gambar 3. Jumlah minat pada topik yang tercantum dalam Renstra dan di luar renstra 20152018.

Gambar 3 memperlihatkan bahwa persentase topik koleksi yang dipinjam pemustaka yang terdapat dalam renstra lebih banyak yaitu sebesar $78 \%$ dibandingkan dengan topik yang di luar renstra yaitu sebesar $22 \%$. Hal ini menunjukkan adanya keterkaitan antara kebutuhan informasi/rujukan dengan kegiatan penelitian yang sedang dilaksanakan baik untuk kegiatan bahan rujukan penelitian maupun dalam penulisan laporan atau karya tulis.

\section{KESIMPULAN}

Koleksi yang dibutuhkan oleh pemustaka BBRBLPP sangat erat kaitannya dengan kegiatan penelitian yang sedang dilakukan sehingga perlu dilakukan pengembangan atau pengadaan koleksi sesuai dengan komoditas kegiatan penelitian. Rencana Startegis (Renstra) BBRBLPP dapat digunakan sebagai acuan untuk rencana pengembangan koleksi sehingga koleksi yang disediakan sesuai dengan kebutuhan pemustaka di BBRBLPP.

\section{SARAN}

Adanya topik yang tercantum dalam renstra BBRBLPP 2015-2018 tetapi sedikit jumlah peminjamannya perlu dikaji ulang selanjutnya.

\section{DAFTAR PUSTAKA}

C_-__- 2017. Peraturan Kepala Perpustakaan Nasional Republik Indonesia nomor 14 tahun 2017 tentang Standar Nasional Perpustakaan Khusus. Jakarta: Perpusnas RI

Basuki, S. 1991. Pengantar ilmu perpustakaan. Jakarta: Gramedia Pustaka Utama.

BBRBLPP. 2018. Rencana Strategis tahun 2015-2019 BBRBLPP. Gondol: BBRBLPP.

Deanawa, N.A. 2017. Analisis kebutuhan informasi. Skripsi. Unair. Surabaya. http//: repository.unair.ac.id

Devadason, F.J. 1996. A Methodology for the Identification of Information Needs ofUsers,62nd IFLA General Conference -Conference Proceedings August 25-31.

Fatmawati, E. 2016. Kebutuhan informasi pemustaka dalam teori dan praktek. Info Persada Vol 13, No 1 (2015). http://e-journal.usd.ac.id/index.php/ Info Persadha/article/view/119/106. [ diakses pada tanggal 4 Mei 2019]

Ishak. 2006. Kebutuhan informasi mahasiswa program pendidikan dokter spesialis (ppds) fk-ui dalam meneliti tugas journal reading. Jurnal Studi Perpustakaan dan Informasi, $\mathrm{V}$ o I . 2 / N o . 2 / Desember. repository.usu.ac.id/bitstream/ 123456789/17058/1/pus-des2006-3.pdf [diakses tanggal 7 Mei 2019]

Kadir, A. 2002. Pengenalan sistem informasi. Yogyakarta: ANDI.

Krikelas, J. 1983. Information seeking behavior: pattern and concepts. Drexel Library Quarterly, 19 (2) https://issuu.com/tigrey/docs/gaalliance.com [diakses tanggal 6 Mei 2019]

Maraharja, D. 2013. Faktor-faktor pemanfaatan koleksi buku perpustakaan oleh peserta didik dalam kegiatan belajar mengajar di SMP Ananda Bekasi. www.lib.ui.ac.id/naskahringkas/2016-03/S46030David\%20Maraharja [diakses tanggal 7 Mei 2019] 
Puspitasari, D. 2015. Mewujudkan liason librarian dalam perpustakaan perguruan tinggi. Acarya Pustaka Volume 1, No. 1, Juni 2015. https:// ejournal.undiksha.ac.id/index.php/AP/article/view/ $\underline{7148 / 0}$ [diakses tanggal 18 juni 2019]

Qalyubi, S, dkk. 2007. Dasar-dasar ilmu perpustakaan dan informasi. Yogyakarta: Jurusan IImu Perpustakaan dan Informasi Fakultas Adab UIN Sunan Kalijaga Yogyakarta.

Siregar, B. 1998. Pembinaan koleksi Perpustakaan dan Pengetahuan Literatur. Medan: Perpustakaan Nasional Propinsi Sumatera Utara

Sutarno, N.S. 2005. Perpustakaan dan masyarakat. Jakarta: Yayasan Obor Indonesia

Winoto, Y. dan Sukaesih., (2016). Studi tentang kegiatan pengembangan koleksi (collection development) pada perpustakaan perguruan tinggi di Wilayah Priangan Timur Provinsi Jawa Barat. Khizanah Al-Hikmah Jurnal IImu Perpustakaan, Informasi, dan Kearsipan, 4(2). journal.uinalauddin.ac.id/index.php/khizanah-al-hikmah/article/view/1749 [diakses tanggal 18 juni 2019]

Yusup, P.M. 2009. IImu informasi, Komunikasi dan Kepustakaan. Jakarta: Bumi aksara. 